\title{
Potential impact of a low emission zone on street-level air quality in Barcelona city using CALIOPE-Urban model
}

\author{
J. Benavides*1, A. Soret ${ }^{1}$, M. Guevara ${ }^{1}$, C. Pérez García-Pando ${ }^{1}$, M. Snyder $^{2}$, F. Amato $^{3}$, X. Querol $^{3}$, \\ and $O$. Jorba ${ }^{1}$

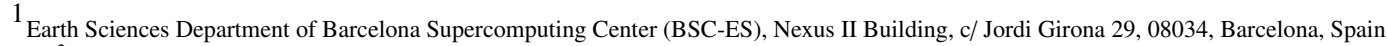 \\ ${ }^{2}$ Institute for the Environment, University of North Carolina at Chapel Hill, 100 Europa Dr. Suite 490, NC 27517, Chapel Hill, USA. \\ ${ }^{3}$ Institute of Environmental Assessment and Water Research (IDAEA-CSIC), c/ Jordi Girona 18-26, 08034, Barcelona, Spain.
}

\begin{abstract}
Barcelona city (Spain) has a very high vehicle density (approx. 5500 vehicles $\mathrm{km}^{-2}$ ) being the majority diesel (64\%). Barcelona traffic stations report chronic exceedances of nitrogen dioxide $\left(\mathrm{NO}_{2}\right)$ European annual regulatory limits since the year 2000. In December 2017, a Low Emission Zone (LEZ) has been implemented in Barcelona to restrict access to the ring-road area to gasoline-powered passenger cars before 2000, diesel passenger cars before 2006 and vans before Euro 1 (registered before 1994) during air pollution episodes. This policy is planned to become permanent on December 2020. This work is an initial step towards evaluating the impact of Barcelona LEZ on air quality using CALIOPE-Urban. CALIOPE-Urban is a street-scale modelling system that couples CALIOPE air quality mesoscale modelling system, which provides air quality forecasts at $1 \mathrm{~km}$ horizontal resolution over Barcelona city, with $R$-LINE. Here we evaluate CALIOPE-Urban and assess its sensitivity to structural reductions of NOx emissions. We evaluate the coupled modeling system using observations from an experimental campaign in April-May 2013 in Barcelona city.
\end{abstract}

\section{Introduction}

A 68\% of Barcelona citizens were exposed in 2016 to $\mathrm{NO}_{2}$ levels above the annual limit (Agència de Salut Pública, 2016). To decrease the negative impact of air pollution on citizens health, Barcelona municipality implemented last December 2017 a Low Emission Zone (LEZ) that focus on its first stage on reducing $\mathrm{NO}_{2}$ levels during air pollution episodes that are expected to occur 2-3 times a year (Barcelona City Council, 2016). This policy is planned to become permanent on December 2020. In the literature, little evidence of the positive impact of LEZs on decreasing $\mathrm{NO}_{2}$ levels has been found in part due to the limited understanding of diesel emission factors under real-world driving conditions (Holman et al., 2015). To evaluate episodic and structural impact on air quality derived from LEZ implementation, a modelling system coupling regional to street scales can provide the necessary information of background pollutant levels and meteorological data to estimate local pollutant concentration gradients using a street-scale dispersion model. In this work, we evaluate CALIOPEUrban system that combines CALIOPE (Pay et al., 2014) with R-LINE (Snyder et al., 2013) adapted to Barcelona street geometrical conditions and we explore the sensitivity of $\mathrm{NO}_{2}$ street concentration levels to a reduction of $\mathrm{NO}_{x}$ emissions as a prior step to analyze the impact of Barcelona LEZ.

*jaime.benavides@bsc.es 


\section{Methodology}

\subsection{CALIOPE air quality system}

The CALIOPE system integrates the Weather Research and Forecasting meteorological model (WRF), the BSC-CNS in-house High-Elective Resolution Modelling Emission System (HERMESv2.0; (Guevara et al., 2013)), the Community Multiscale Air Quality Modeling System (CMAQ) and the mineral Dust REgional Atmospheric Model (BSC-DREAM8b). The mesoscale system runs over Europe at a $12 \mathrm{~km} \times 12 \mathrm{~km}$ horizontal resolution, Iberian Peninsula at $4 \mathrm{~km} \times 4 \mathrm{~km}$, and the Barcelona domain at $1 \mathrm{~km} \times 1 \mathrm{~km}$. CMAQ vertical levels are collapsed from the $38 \mathrm{WRF}$ levels to 15 layers up to $50 \mathrm{hPa}$ with six layers falling within the PBL. CMAQ version 5.0.2 with CB05 chemical mechanism and AERO5 aerosol scheme is used.

\subsection{CALIOPE-Urban}

The combination between CALIOPE and R-LINE, CALIOPE-Urban, requires the use of CMAQ for background concentration data and WRF for meteorological inputs. WRF bottom layer over the street of interest is used as boundary conditions for R-LINE local meteorology module. With respect to background concentrations, the upwind urban background scheme is applied. The upwind background scheme chooses CMAQ grid cell values depending on wind speed and direction. R-LINE hourly emissions inputs for each road segment are provided by HERMES that produces specific hourly emissions for each street segment. R-LINE is run using the numerical integration approach to solve Gaussian dispersion equations and the Generic Reaction Set (GRS) for $\mathrm{NO}-\mathrm{NO}_{2}-\mathrm{O}_{3}$ chemical reactions (Azzi and Johnson, 1992). Receptors are located at 3 meters $(\mathrm{m})$ above ground level forming a regular grid of $10 \mathrm{~m}$ horizontal resolution to predict spatial patterns and in specific coordinates to compare with observations.

To evaluate predicted hourly $\mathrm{NO}_{2}$ concentrations we use observations from an experimental campaign conducted in April and May 2013 in Barcelona (Amato et al., 2014). During the campaign, mobile laboratories placed at the parking lane of several street segments measured air quality parameters at $3 \mathrm{~m}$ height. For this study, data gathered every 30 minutes at Valencia Street No. 445 is shown. This street presents a marked canyon pattern where building height to street width ratio is approximately 1 .

As an initial step towards developing a methodology to assess the potential impact of the $\mathrm{LEZ}$ on $\mathrm{NO}_{2}$ concentration levels, in this work we analyze the sensitivity of CALIOPE-Urban to potential reductions of $\mathrm{NO}_{x}$ emissions that could be caused by a policy to improve air quality in the city without taking into account the LEZ at this stage. In the analysis presented here, we only use a mesoscale model run that incorporates the full emissions in the region and we force the street-scale model to use as input explicit emissions for each street segment with a reduction of $15 \%$. This is a preliminary methodology to address the question of the effectiveness of such measure. In a future work, the reductions will be considered both in the mesoscale and urban scale models.

\section{Preliminary results}

We start by assessing the ability of the model to represent spatial and temporal variability of $\mathrm{NO}_{2}$ concentrations in Barcelona, then we analyze the sensitivity to a potential reduction of $\mathrm{NO}_{x}$ emissions. Figure 1 shows the spatial detail provided by street-scale and mesoscale combined solutions over Eixample district for 8 UTC 9 April 2013. The increased resolution of street-scale makes possible to visualize $\mathrm{NO}_{2}$ street gradients. 


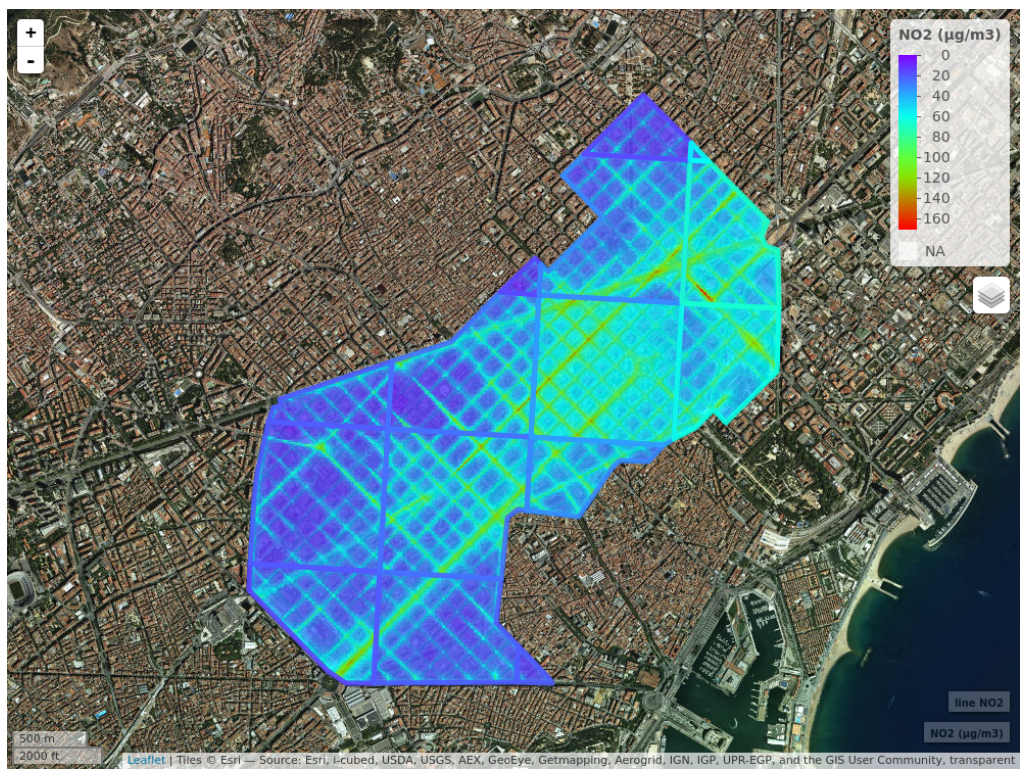

Figure 1: $\mathrm{NO}_{2}$ hourly level at 8 am (UTC) on 9 th April 2013. Squares represent mesoscale $1 \mathrm{~km} \mathrm{x} 1 \mathrm{~km}$ grid cell values and the inside content street-scale concentrations.

To visually analyze hourly $\mathrm{NO}_{2}$ temporal variation of the models and to evaluate the sensitivity of the system to changes in $\mathrm{NO}_{x}$ emissions we use observations from the highly trafficked experimental campaign site of Valencia street, which has an average daily traffic of 32500 vehicles and represents the typical street canyon pattern with an average of $20 \mathrm{~m}$ building height and $20 \mathrm{~m}$ street width, during the period 4-8 April 2013. This period and site are chosen because they represent the main $\mathrm{NO}_{2}$ concentration patterns found during the experimental campaign in the most extended geometry of the city (i.e. Eixample district). Figure 2 shows observed $\mathrm{NO}_{2}$ concentration levels (black) compared to CALIOPE (blue), CALIOPEUrban (red) and for the street-scale model using reduced $\mathrm{NO}_{x}$ emissions of $15 \%$ (green). From Figure 2 we can see a high difference in performance between mesoscale (blue) and street-scale (red) models. Overall mesoscale is systematically under-predicting the concentration during the central hours of the day and is not able to capture the peaks. In contrast, street-scale represents more precisely the measured diurnal variation, giving estimates on weekdays in accordance with observations levels and a better reproduction of peak values. For example, on the 8th at 6 am (UTC) a concentration peak found in observations $\left(136.5 \mu \mathrm{g} / \mathrm{m}^{3}\right)$ is better reproduced by street-scale $\left(128.7 \mu \mathrm{g} / \mathrm{m}^{3}\right)$ than by mesoscale $\left(72.4 \mu \mathrm{g} / \mathrm{m}^{3}\right)$. It is also remarkable the improvement of CALIOPE-Urban during the central hours of the day.

With regard to $\mathrm{NO}_{2}$ sensitivity to a $15 \%$ decrease in $\mathrm{NO}_{x}$ emissions, we see that $\mathrm{NO}_{2}$ levels systematically decrease following the same dynamics as the street-scale model with full $\mathrm{NO}_{x}$ emissions. Furthermore, on a simulation executed for the entire period of April and May 2013 we find an average difference between the $\mathrm{NO}_{2}$ concentration outputs of these two model configurations of $5 \mu \mathrm{g} / \mathrm{m}^{3}$ producing lower concentration values with the reduced emission configuration, a significant reduction of $\mathrm{NO}_{2}$ levels taking into account the limitation that CMAQ was executed with full emissions and used for background concentrations in both model runs. 


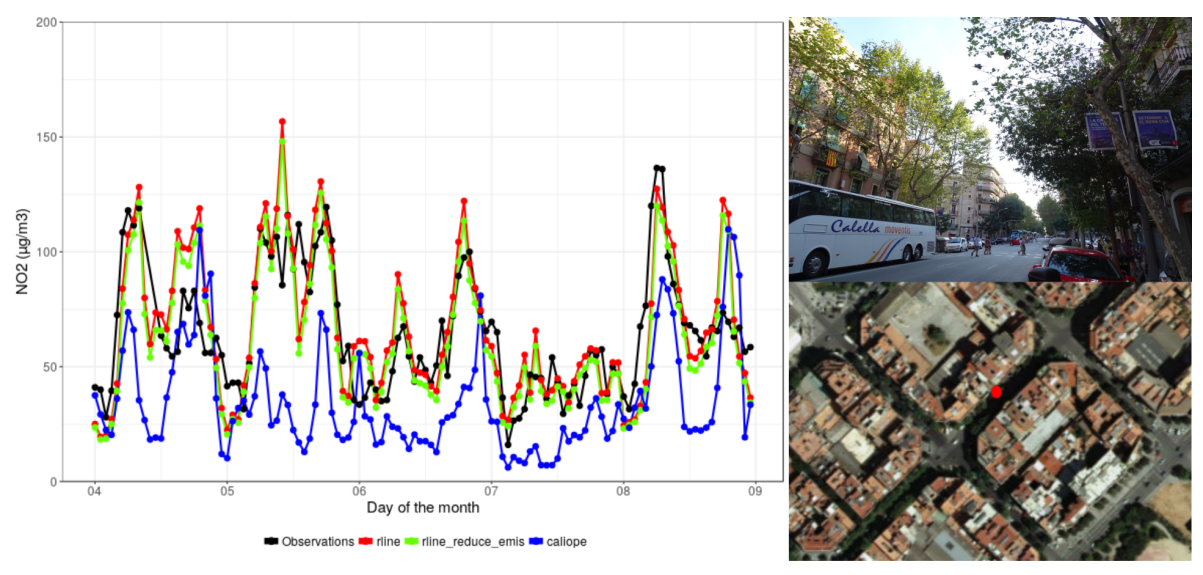

Figure 2: $\mathrm{NO}_{2}$ temporal variation for the period 4-8 April 2013 in Valencia Street No. 455. Left panel shows the comparison between model configurations. On the right side, the top image is the site street canyon and the bottom image is the site seen from above. (Observations shown in BLACK, street-scale model in RED, street-scale model with reduced NOx emissions in GREEN and mesoscale in BLUE).

\section{On going work}

Next steps are directed to decrease the emission uncertainties by integrating in the system new emission and traffic data that has been collected in Barcelona, permitting the inclusion of more realistic emission factors, traffic composition and intensity. Then, we will apply this new emission inventory to assess the potential impact on $\mathrm{NO}_{2}$ concentration levels of the LEZ in Barcelona by simulating the effect of restricting the entrance to the ring-road to the banned vehicles. We will integrate the emissions in both the mesoscale and the local scale model runs.

\section{Acknowledgements}

BSC researchers acknowledge the grants CGL2013-46736-R, CGL2016-75725-R and COMRDI15-1-0011-04 of the Spanish Government. Jaime Benavides $\mathrm{PhD}$ work is funded with a grant from the FPI Programme by the Spanish Ministry of the Economy and Competitiveness, call 2014, with reference EEBB-I-17-12296.

\section{References}

Agència de Salut Pública (2016). Avaluació de la qualitat de l'aire a la ciutat de Barcelona. Technical report, Agència de Salut Pública, Barcelona.

Amato, F., Karanasiou, A., Cordoba, P., Alastuey, A., Moreno, T., Lucarelli, F., Nava, S., Calzolai, G., and Quero, X. (2014). Effects of Road Dust Suppressants on PM Levels in a Mediterranean Urban Area. Environmental Science E Technology, 48(14):8069-8077.

Azzi, M. and Johnson, G. (1992). An introduction to the generic reaction set photochemical smog mechanism.pdf. In Proceedings of the 11th International Clean Air Conference, number August, pages 451-462.

Barcelona City Council (2016). Mesura de govern: Programa de mesures contra la contaminació atmosfèrica. Technical report.

Guevara, M., Martínez, F., Arévalo, G., Gassó, S., and Baldasano, J. M. (2013). An improved system for modelling Spanish emissions: HERMESv2.0. Atmospheric Environment, 81:209-221.

Holman, C., Harrison, R., and Querol, X. (2015). Review of the efficacy of low emission zones to improve urban air quality in European cities. Atmospheric Environment, 111:161-169.

Pay, M. T., Martínez, F., Guevara, M., and Baldasano, J. M. (2014). Air quality forecasts on a kilometer-scale grid over complex Spanish terrains. Geoscientific Model Development, 7(5):1979-1999.

Snyder, M., Venkatram, A., Heist, D., Perry, S., Petersen, W., and Isakov, V. (2013). RLINE: a line source dispersion model for near-surface releases. Atmospheric Environment, 77:748-756. 